\title{
Review on Manufacture of Military Composite Helmet
}

\author{
Yazhen Liang $^{1} \cdot$ Xiaogang Chen $^{1}\left[\right.$ Constantinos Soutis $^{1}$
}

Received: 19 May 2021 / Accepted: 18 July 2021 / Published online: 30 October 2021

(c) The Author(s) 2021

\begin{abstract}
Despite of the fact that more and more accessory devices are integrated to functionalize a ballistic helmet system, its core ballistic protective function needs to be improved with weight reduction was and still is the main course in engineering design. The two major generic classes of synthetic fibres for ballistic composites are Ultra High Molecular Weight Polyethylene (UHMWPE) fibre $\left(0.97 \mathrm{~g} / \mathrm{cm}^{3}\right)$ and aramid fibre $\left(1.44 \mathrm{~g} / \mathrm{cm}^{3}\right)$. In the area of military helmets, these fibres are constructed into different topologies, draping/forming into double-curvature geometric shape in multiple plies, serving as reinforcement for composite shell. The preforming ways influence the subsequent impregnation / solidification and curing step in manufacture, in terms of the fibre orientation and fibre volume fraction. The inherent structural heterogeneity thus leads to scatter in permeability and composite thickness, and have further impact in generating process-induced defects. During the processing, the fibre continuity without wrinkles, together with voids-free are determinative factors to a quality final part. The aim of this paper is to review the manufacturing technologies characterised by thermo-mechanical forming and Liquid Composite Moulding (LCM), relating their processing parameters respectively to the properties of reinforcements in one dimension (1D), two dimensions (2D) and three dimensions (3D), along with that of the matrix in dry or wet phase, interdependency of them are sought.
\end{abstract}

\section{Introduction}

The factors considered in engineering design of military composite helmets for modern society have a much broader spectrum [1-3], focusing not only on the ballistic resistance [4], coverage [5] and curvature [6], but also on the comfort to the wearers [7], and the compatibility with more and more desirable accessory devices [8]. These will make the design a complex issue, while providing more freedom for designers. Most of all, achieving a helmet shell with sufficient ballistic resistance was and still is the priority task.

To improve the ballistic resistance, a wide range of experimental and simulation works across various disciplinary sections have been done in literature. These works could be subcategorized into the studies of material impact failure mechanisms [9, 10], fibre

Xiaogang Chen

Xiaogang.Chen@manchester.ac.uk

1 Northwest Composite Centre, Department of Materials, University of Manchester,

Manchester M13 9PL, UK 
surface frictional treatments [11, 12] fibre architecture parametric analysis [13], draping (forming) [14] and ply-ply sliding [15] in preforming, hybrid materials [16], resin enhancement [17] and manufacturing method optimization [18, 19]. These materialrelated engineering results were validated by the investigation on the interaction between helmet shell and human brain [20], where the blunt traumatic injuries and bone fracture [21] was simulated based on different types of head forms [22], or tested by the way of energy absorption [23]. To sum up, the protective ability improvement is largely dependent on the tensile strength and modulus of the fibres used, along with the type of resin which is used to adhere these fibres together.

Some reviews in the literature investigated the manufacturing methods for thermoset which was closely related to the resin filling process taking account for variability of dry prepregs and the uncertainty in draping [18]. While the review on forming include the knowledge of material mechanical properties verification [24]. There is also review on the link between the helmet and head injuries as well [25]. However, these works have not covered the fabric types correlate to the manufactures in specific mechanisms. This review will based on the interdependency of materials properties, fibre architectures, preforming and manufacturing methods. The manufacturing rules in the fields of complex shaped composite parts (i.e. hemispherical, domed), will be covered.

\section{Primary Requirements}

During the projectile penetrating textile-based materials [26], the strain propagates away from the impact point along the axis of yarn, simultaneously the strain also develops at opposite to the projectile flying direction to deflect the stress thus create the transverse wave velocity, see Fig. 1. From the strain wave propagating direction, it is cleared that the longer fibre, the better energy absorption. Thus, fibre continuity is desirable in reinforcements [23], it should be maintained throughout the whole manufacture without disturbance.

A flat fabric with continuous fibres conforming onto the arbitrary shape of surface was described as forming or draping [27]. The preforms free of wrinkles/folding or misalignment serve as an ideal reinforcement for composite, achieving better energy absorption. Shearing is the major mechanism determining the draping behaviour, which can be predicted by bias extension and picture frame test [28]. The mouldability tester was developed as an alternative as well [29].

Fig. 1 Simplified illustration of a projectile impact into a panel. (Courtesy of [26])

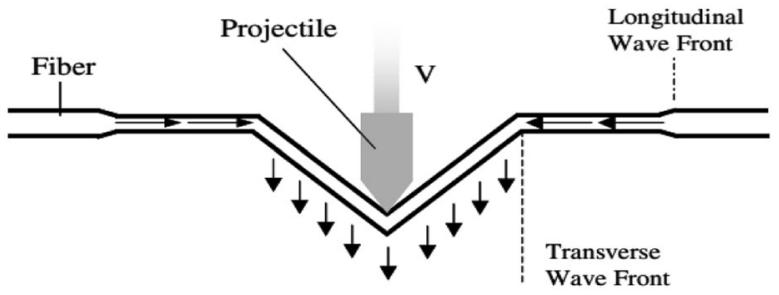




\section{Materials for Ballistic Helmet}

\subsection{Ballistic Fibres}

Among all the synthetic fibres, para-aramid (such as Kevlar, Twaron) fibre $\left(1.44 \mathrm{~g} / \mathrm{cm}^{3}\right)$ gained prevalence in helmet practical use for several decades [30, 31]. Recently, market is shifting to the domination of the crystallized fibrils olefin ethylene UHMWPE (such as Dyneema, Spectra and Endumax) fibres $\left(0.97 \mathrm{~g} / \mathrm{cm}^{3}\right)$, which supersedes para-aramid in both $\mathrm{V}_{50}$ increment and weight reduction. The UHMWPE having high strength to weight ratio characteristic, low coefficient of friction, good cut resistance and creep effect [32], but low melting point (around 145-153 ${ }^{\circ} \mathrm{C}$ ). Creep provides the chance for the fibre being stretched and extended to a certain degree subjecting to some magnitude of strains. However, the UHMWPE based material features higher back face deformation value than that of aramid.

Ascribing to their unique chemical structures where the atoms are held by the strong covalent bonds, the traits of excellent tensile, high modulus and inertia to most of the environments are presenting [30]. Thereof, the ballistic helmets currently can be subcategorized into three types on material-based, namely UHMWPE-based helmet, aramid-based helmet and hybrid helmet combining both of these two materials or others, depicted in Fig. 2.

\subsection{Fibre Architectures}

In application for military helmets, these fibres are constructed into different topologies widely known as woven, unidirectional (UD), braided, stitched, and tufted fabrics [33]. The pores, fibre orientation and fibre volume fraction distribution inside these fabric types present various interconnections and patterns, giving different fluid flow resistance. Besides, the crimps (curvature) level determines the suitability for ballistic application, simultaneously influencing the flow pattern [34] in later resin filling process or response to compression force. These structural heterogeneities lead to scatter in permeability and composite thickness, having further impact in process-induced defects. In this review, the fibre architectures are broken down into the form of one dimensional (1D), two dimensional (2D) (referring to 2D woven, UD shield and films here) and three dimensional (3D) (referring to 3D solid woven, braided, stitched and tufted), to better describe their flexural properties.

Ballistic helmet
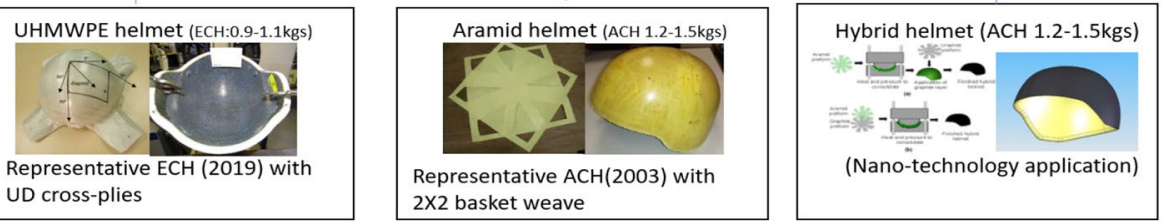

Fig. 2 Subcategories of ballistic helmet on material base (Courtesy of [6, 16, 35]) 


\subsection{Matrices}

As a primary constituent out of two in composite materials, the matrix provides adhesion to hold the fibres in place. The bonding between fibre and matrix offers the interfacial shear strength to lessen the risk of delamination. In the impact event, it also works as a transient medium to transfer the load into the reinforcing fibres. The matrices are characterized into thermoset (rigid) and thermoplastic (flexible) matrix. The major types and properties of resin used for ballistic shown in Fig. 3.

\section{Preforming}

Preforming is a process to prepare the $1 \mathrm{D}, 2 \mathrm{D}$ and 3D fabric in a near-net-shape without changing the microstructure, fibre continuity, and free of wrinkles and fibre distortion. The different structural flexural capability are discussed, the fibre natural properties are assumed to be neglected. Preforming takes up around $60 \%$ of total helmet manufacturing time [1]. It is not easy to prepare a highly double curled dome with large locking angle (normally $>50^{\circ}$ degree).

\subsection{D Fibre Architecture Preforming}

In the plural filament deposition (see Fig. 4a and b), the continuous filaments are blew and deposited onto the helmet-shaped porous screen, with the resinous solution sprayed onto the preform plies prior to or after the deposition [37]. While the filament winding [32, 8] is arranged with the fibre orientation and distribution in a controlled manner (see Fig. 4c and d), and different winding patterns were proposed (see Fig. 4e and f) [38, 39]. Despite of fibre continuity retained and inter-plies sliding was mitigated, the drawback of this preforming is high pore contents that might developed into resin rich area.

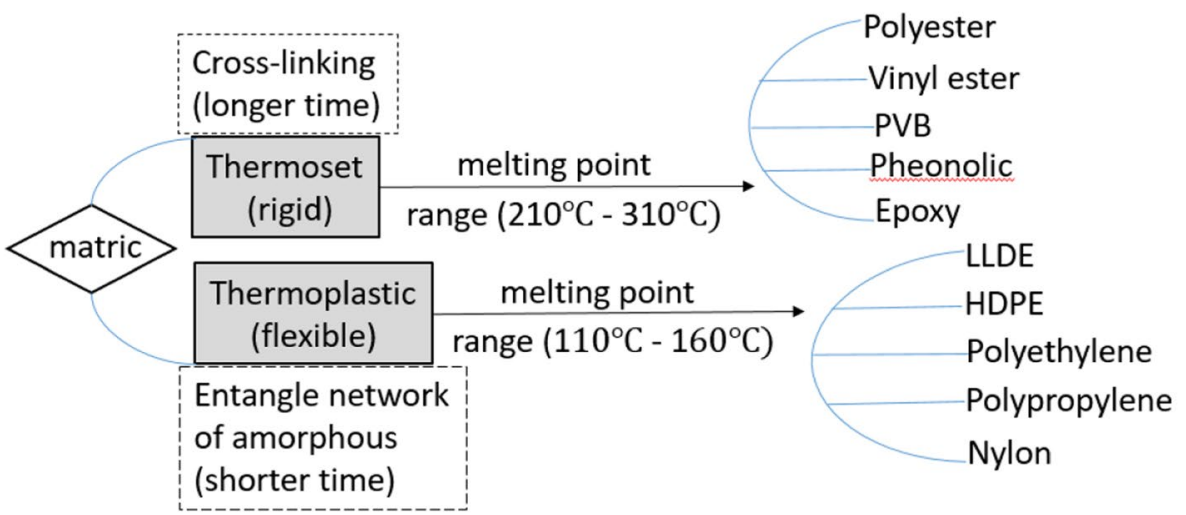

Fig. 3 Common types of thermoset and thermoplastic matrices for ballistic composite [36] (PVB: polyvinyl butyral; LDP: low density polyethylene; EVA: Ethylene-vinyl acetate) 


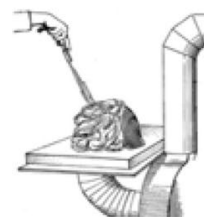

(a)

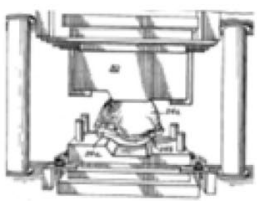

(b)

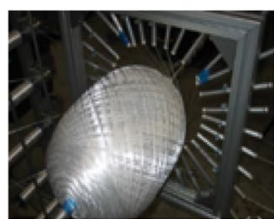

(c)

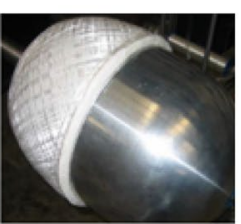

(d)

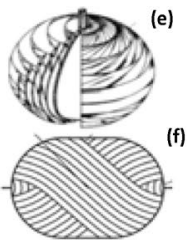

(f)

Fig. 4 Plural filament deposition preforming (a), compressed moulding (b) [37]; Filament winding preforming (c), followed by 'fibre weld' after cutting (d) [32]; Alternative winding patterns (e) (f) [38, 39]

\subsection{D Fibre Architecture Preforming}

To mitigate the wrinkles/folding and evenly distribute the fibre volume fraction, cut-dart technique was conventionally used, mainly for inextensible 2D woven aramid based preforms, with various petal patterns designed (zig-zag-petal [40], curled cut pedal [41], 4-petal [42] and pin-wheel [31]), see Fig. 5a-d. 4-petal pattern was said to be the one most reducing scrap and offset the seam intensity.

The cut-dart technique is also suitable for the hybrid helmet preforming, see Fig. 5e. Regardless of the layers staggering was expected to offset the seams effects, the cut-dart inevitably resulting in the fibre discontinuity. To ease this discontinuity, one trial was made by a combination of the plain, twill and satin weave in one dome shape patchy [43]. While for the highly oriented UHMWPE-based 2D UD shields/films, the manufacturing ways are normally utilise its extensibility in nature (i.e. crimp effect), processed with facilitators of tooling and blank holders [44], with friction accounted.

\subsection{D Fibre Architecture Preforming}

3D fabrics are enhanced in out-plane properties to mitigate the delamination, having advantages of making near-net-shaped preforms. 3D woven includes the types of solid, hollow, shell and nodal [43, 45]. Among of them, the interlock fabric having good mouldability then suitable for complex shape forming [46-48], with the structural integrity and fibre continuity maintained. The solid orthogonal has been studied for forming over hemisphere but quite shallow in depth [49]. The 3D braided fabric has capability of highly deformation, but might couple with potential defects, specially buckles [50]. In terms of the 3D stitched fabric (also called non-crimp fabric (NCF)), optimal stitching patterns (i.e. pillar) can facilitate forming of multiply preforms [44], and the blank holder forces can also lessen the inherent asymmetrical shear behaviour [51]. Alternatively, the tufting $[52,53]$ is also used to enhance the through-thickness property as well

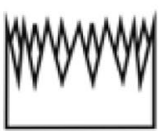

(a)

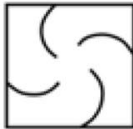

(b)

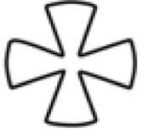

(c)

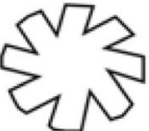

(d)

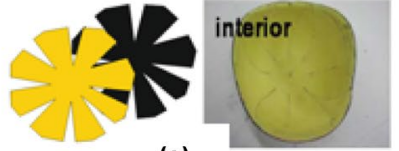

(e)

Fig. 5 Cut-dart patterns (a) Zig-Zag petal (b) Curled Cuts pedal (c) 4-pedal pattern (d) pin-wheel (e) Hybrid helmet (Courtesy of [40-42, 40, 16]) 
Table 13 D fabric used for complex shapes forming.

\begin{tabular}{|c|c|c|c|c|c|c|}
\hline Types & Feature & Architecture & Diagram & $\begin{array}{c}\text { Hemispherical } \\
\text { shape }\end{array}$ & $\begin{array}{c}\text { Interlacing } \\
\text { points }\end{array}$ & Sources \\
\hline \multirow{5}{*}{$\begin{array}{c}\text { 3D } \\
\text { Woven }\end{array}$} & \multirow{3}{*}{ Solid } & TTAI & 20. [43] & & Mediate & [46] \\
\hline & & LLAI & 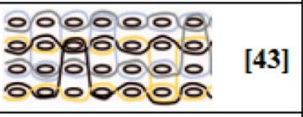 & & High & [48] \\
\hline & & Orthogonal & $\frac{10000000}{0.000000}$ & & Media & [49] \\
\hline & Hollow & Multilayer & 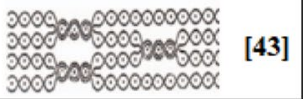 & & High & \\
\hline & Shell & Single layer & {$[45]$} & & High & [45] \\
\hline Braiding & Solid & Multilayer & {$[50]$} & & High & [50] \\
\hline Stitching & Solid & $\begin{array}{l}\text { Unidirectional } \\
\text { plies with } \\
\text { pillar stitches }\end{array}$ & [51] & & Low & [51] \\
\hline Tufting & Solid & $\begin{array}{c}\text { Fabric } \\
\text { enhanced with } \\
\text { tufting }\end{array}$ & [53] & & Low & [53] \\
\hline
\end{tabular}

as to ease the wrinkles, however, the yarns are risk of being damaged. Many physical specimens in complex shapes were demonstrated in Table 1.

\section{Manufacturing Methods}

The manufacturing methods are used to handle the preforms and matrix systems in a proper way to achieve an optimal relationship between them. A process named after a unique characteristic in one paper might just labelled with a different acronym in another. For example, the Vacuum Assisted Resin Transfer Moulding (VARTM) and Resin Infusion under Flexible Tooling (RIFT) [54] share the same fundamental principles. Thus, one primary task of current review is to characterize these manufacturing methods. The machine, tools, energy supply systems or operations used for one of the methods, might also be suitable for the other, the boundaries are not clear among of them. However, one underlying factor influencing the selection of desirable method and parameters is the phase of the matrix (solid or liquid). On this base, the manufacturing methods are divided into two categories, namely the thermo-mechanical forming which is handling the solid dry prepreg and the Liquid Composite Moulding (LCM) deals with the wet resin filling, as listed in Fig. 6. 


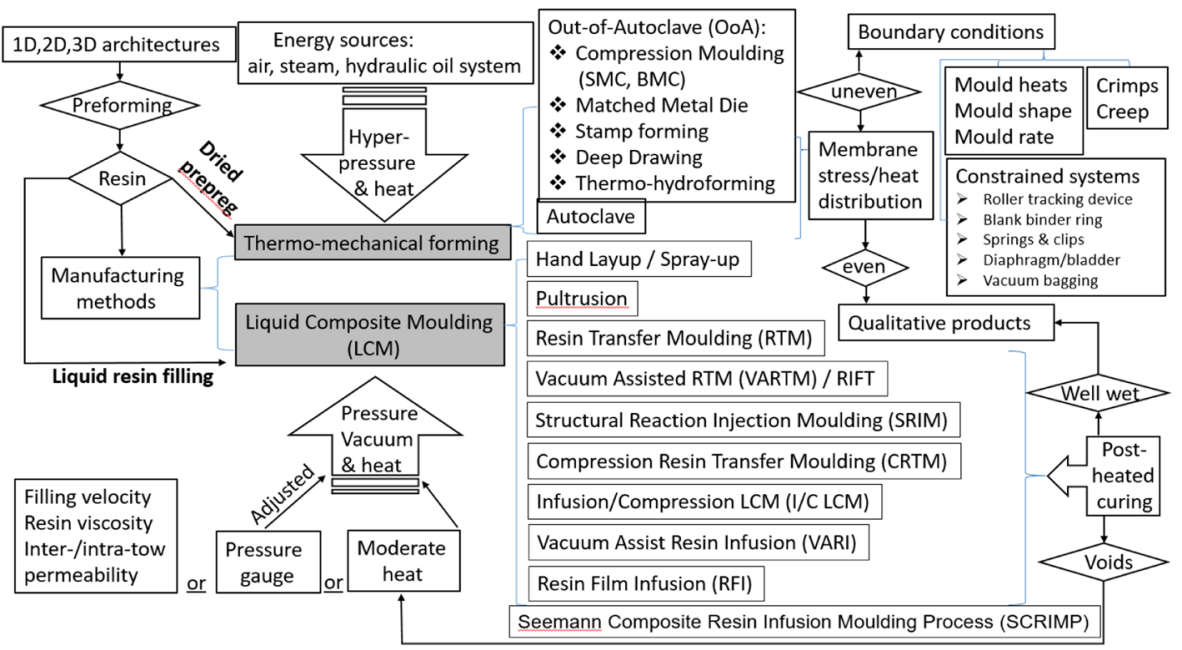

Fig. 6 Schematic demonstrate the manufacturing methods (subcategorized into Liquid Composite Moulding (LCM) and thermo-mechanical forming)

\subsection{Thermo-Mechanical Forming}

This is a fairly quick process, carried out by the chance of extensibility which is largely depend on the tensile, compressive and creep [55] properties of materials (i.e. UHMWPE), or by inter-yarn sliding and rotation for those virtually inextensible materials (i.e. aramid), both dominated by shear deforming mechanisms. The preforms present as prepreg are coated with semi-crystalline resin on the surface in half cure, the resin is melt and interact with fibres subjecting to the heat and pressure compression. Shorter resin flow in this process will contribute to nearly void free final part.

\subsubsection{Machine Set Up (Autoclave and Out-of-Autoclave)}

5.1.1.1 Autoclave / Compression Moulding / Matched Metal Die Autoclave [56] is an equipment that can produce more sophisticated, high quality and complex geometric parts thanks to its uniformly heat and pressure supply system (radiation take up 60\% of total amount of heat transfer [57]). But the investment on autoclave equipment itself is relatively heavy, so that the out-of-autoclave (OoA) techniques were developed as alternatives.

Among the OoA processes, the compression moulding [58] and match metal die [59] are equipped with a pair of mould (the male can be metal or rubber). A so-called hydrostatic resin pressure might force the reinforcement back from its right place inducing wrinkles [60]. These are conventional methods widely adopted for manufacturing aramid-based PASGT or ACH with prepreg in cu-dart patterns [30,61], see Fig. 7a. Without cut-dart, the prepreg prone to have excess materials accumulation around the spherical brim as no clamping devices used [59], see Fig. 7b. Both techniques featuring high fabric-mold friction, thickness variability, longer cycling time as heating and cooling in one system. 


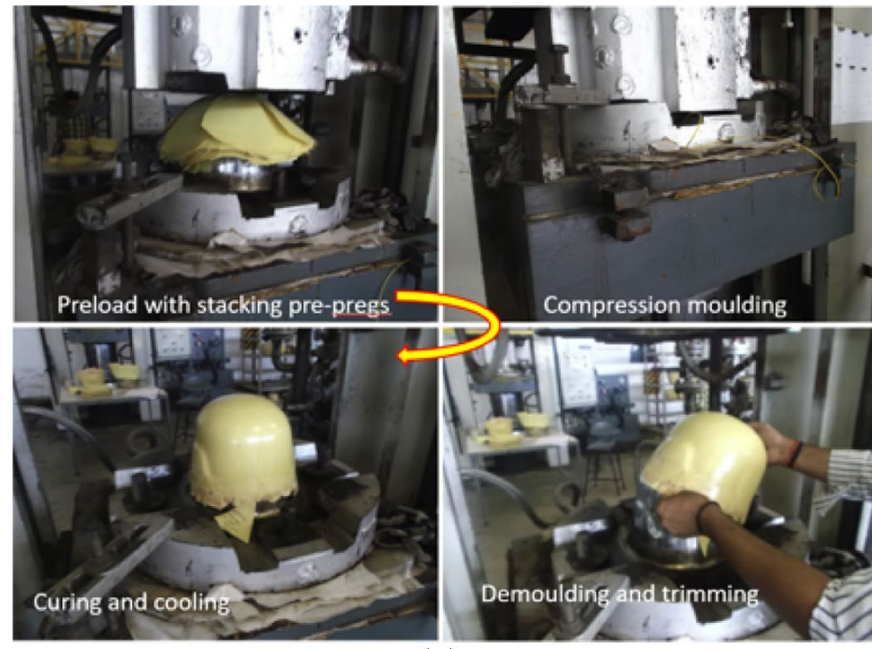

(a)

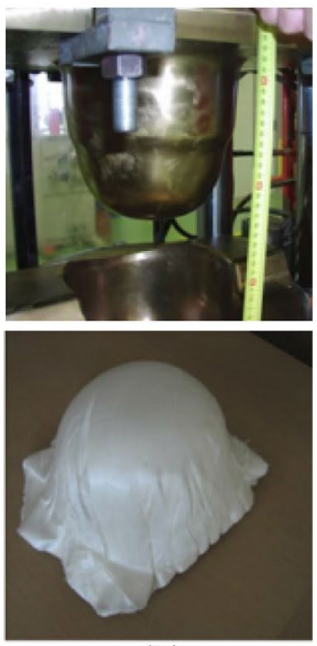

(b)

Fig. 7 (a) Compression moulding for 2D woven aramid prepreg in cut patterns (Adapted from [30]); (b) Matched metal die forming (Courtesy of [59])

5.1.1.2 Stamp Forming / Deep Drawing / Thermo-Hydroforming Stamp forming [62] and deep drawing (a draw depth to radius of 16:10) [63,64] are set up with blank holder for prepreg restraining [51]. Compressive membrane stress was reported to responsible for wrinkles subjecting to shearing [65]. These methods are good for thin materials in lower fibre content [66], but limited in use for more complex shaped and large thick parts. Thermohydroforming is then developed with stronger and flexible constraining devices to achieve shaped variants [19, 67], the principles of it are demonstrated in Fig. 8d. The female part can be replaced by cycled hot/cool air/steam/hydraulic oil and prepreg sealed with flexible rubber diaphragm, bladder or membrane, eliminating the scratches associated with the traditional compression matched metal dies, and reduce 50\% cost of equipment. The drawbacks include an oil leaking into punch cavity as high pressure lift the blank [19], a punch displacement of $50 \mathrm{~mm}$ needs relatively high force $1200 \mathrm{~N}$ [68].

\subsubsection{Energy Supply Systems}

The energy systems typically can be that of air, steam and oil based set up. But the outcomes of them have not been satisfactory, such as damage helmet crown in air-based system ascribing to too high and non-distributed temperature and creep [63], insufficient creep amount around the hemisphere and fibre breaking near the crown in steam assisted system [59], and the variable of shape (i.e. the ear position) feasibility is unclear and likely oil leaking in hydraulic oil backing system [19], depicted in Fig. 8c-d. Thus, an ideal set up might be a combination of traditional compression moulding with hydraulic oil-based moulding. 


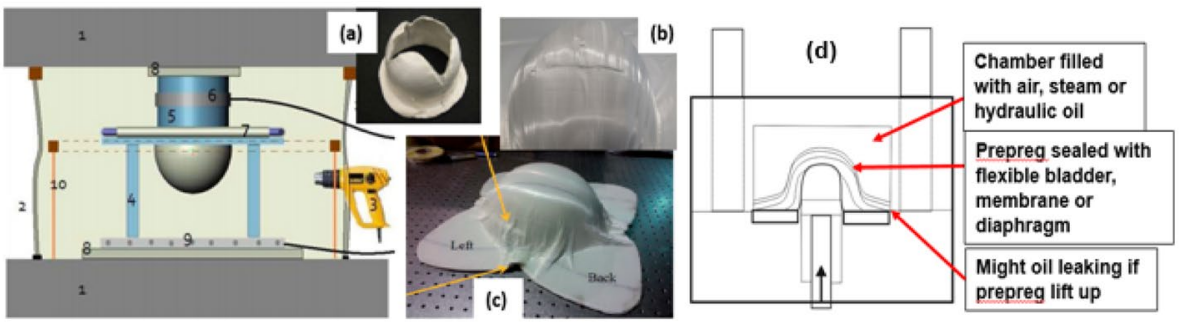

Fig. 8 (a) Air-based system (Courtesy of [63]) (b) Steam-based system (Courtesy of [59]) (c) Hydraulic oil-based system (Courtesy [19]) (d) Thermo-hydroforming set up (Courtesy of [71]).

\subsubsection{Additional Constrain Systems}

On the other hand, a range of constrain systems useful for suppressing the process-induced defects, and trade-off the high production rate against affordable machinery, were developed [69]. The evidences also found that approximate $20 \mathrm{MPa}$ in-plane stress can have a positive effect on wrinkle-free part with shearing angle around $60^{\circ}$ [70]. The variants of the constrain system are listed in Table 2.

The clamping devices that are suitable for holding the thin ply including roller tracking device [66], springs and clips with avoiding fabric-tool friction [35]. The blank binder rings system with larger holder size and adjustable pressure are preferable, to satisfy the uneven strain distribution during deforming [51]. The diaphragm [57] is a sophisticated

Table 2 Constrain system variants in literature.

\begin{tabular}{|c|c|c|c|c|}
\hline & Blank binder ring & Frame holding & Frame winding & Diaphragm / bladder \\
\hline set up & 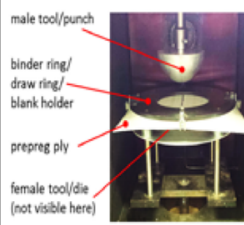 & tisting & & Clemping ring \\
\hline $\begin{array}{l}\text { Preforms } \\
\text { thickness } \\
\end{array}$ & Thick & Thick & Thick & Thick \\
\hline \multirow[t]{2}{*}{ Sources } & {$[64]$} & [63] & [63] & {$[57]$} \\
\hline & Vacuum Bagging & Springs & Springs \& clips & Roller tracking \\
\hline Set up & 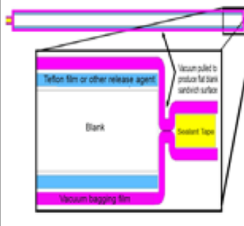 & & & 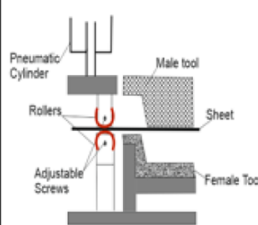 \\
\hline $\begin{array}{l}\text { Preforms } \\
\text { thickness } \\
\end{array}$ & Moderate & Moderate & Thin & Thin \\
\hline Sources & [19] & [35] & [72] & {$[66]$} \\
\hline
\end{tabular}


Related to laminate thickness / Bending stiffness

\section{Deform mode}

Tensile in warp and weft

in-plane shear

transverse compression

transverse shear

Fig. 9 Schematic deform mode in thermo-mechanical forming process

arrangement work well for thick plies formation, however, costly. Alternatively, vacuum bagging film is one of the choice to replace the diaphragm/bladder constraining $[19,57]$.

\subsubsection{Prepreg Deform Mechanisms, Defect Sources and Calibrating Tools}

5.1.4.1 Deformation Mechanisms The deformation mechanisms of thermo-mechanical forming were fully reviewed in [73], the progressively developing deform mode was depicted in Fig. 9. The process is largely dependent on the physical change of material tensile properties (such as creep) under moderate heat and pressure, and intra-/inter ply shear caused by sliding, followed by transverse compression and bending [73]. The latter is mostly related to laminate thickness and bending stiffness [69]. In these physical change, friction plays an importance role in dominating the forming process of $1 \mathrm{D}, 2 \mathrm{D}$ and $3 \mathrm{D}$ structures. The friction include that generated between fabric and tool [75].

In mesoscale, the deformation resistance in biaxial woven fabric comes from the friction at crossover points $[13,76]$. The Pin Join Net (PJN) is a typical model for explaining the shear behaviour of woven fabric (sliding between the weft and warp yarn at crossover point), with the shearing angle being used as one of the indicators. While in unidirectional laminate, the PJN model may also valid especially in those with relatively high inter-ply friction, where $[0,90]$ and $[45,-45]$ cross-ply were reported as this case. This is align with the result that lay-up sequences influence the wrinkles formation [14]. In macroscale, the friction and shear behaviour of fabric generate the in-plane membrane stress [65] when subjecting to the normal force and then give significant impact during forming $[14,15,78]$.

Table 3 Potential defeats characterization in thermo-mechanical forming

\begin{tabular}{|c|c|c|c|c|c|}
\hline Pref & orms & Defec & & Sources & Potential detriments \\
\hline \multirow{4}{*}{ Woven } & \multirow{4}{*}{ |: } & In-plane waviness & & Load path and compressive strength & \multirow{7}{*}{$\begin{array}{l}\text { Lost tensile strength; induce } \\
\text { discontinuity; affecting } \\
\text { compression after impact; } \\
\text { resin rich area }\end{array}$} \\
\hline & & Breakage & & $\begin{array}{l}\text { Load path, compressive strength, } \\
\text { frictional contact between metal punch } \\
\text { and preforms }\end{array}$ & \\
\hline & & Slippage & & Load path, yarn sliding & \\
\hline & & Jamming & & Beyond locking angle & \\
\hline \multirow{3}{*}{\begin{tabular}{c|} 
Highly \\
oriented \& \\
unidirectioal
\end{tabular}} & \multirow{3}{*}{ 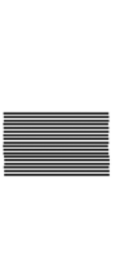 } & Wrinkling & & Load path, compressive strength & \\
\hline & & $\begin{array}{l}\text { Thickness non- } \\
\text { uniformity }\end{array}$ & & Load path, compressive strength & \\
\hline & & Buckling & 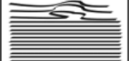 & $\begin{array}{l}\text { Load path, un-uniformility of strain } \\
\text { distribution, fibre/ply sliding }\end{array}$ & \\
\hline
\end{tabular}


5.1.4.2 Defects Categories and Sources The response behaviours of 1D, 2D and 3D preforms isolate various relative defects, including those list in Table 3. These material-dependent defects might come from many sources, which are closely relating to machine setting and processing variables, such as temperature and heat-transer, tool velocity, lateral restrains from dies, pre-tension from different type/sizes/holding time of clamps, where friction interaction is underlying [62]. The different coefficients of thermal expansion (CTE) between tool and prepreg, or that between fibres and matrix will further induce residual stress [79, 80], apart from the other sources of materials shrinkage, processing temperature, cooling rate and oxidation environment.

\subsection{Liquid Composite Moulding (LCM)}

Typically, the liquid resin handling techniques are widely well known as Liquid Composite Moulding (LCM). The methods categorized in LCM family having the traits of dry fabric preloaded in the design moulding, resin filling drawn by boundary conditions to wet the dry preforms in the closed (matched metal dies) or opened moulds (vacuum polymeric bag), well wetting of the preforms and the curing degree are the primary concerns.

\subsubsection{Manufacturing Techniques}

5.2.1.1 Pultrusion / Hand Layup / Spray-Up Among this class, some methods are not demonstrating its suitability for ballistic helmet manufacturing in reasons. The pultrusion [81] with capability of producing constant cross section only is limited for complex shaped manufacturing, while hand layup and spray-up having chance of uneven resin distribution together with volatile styrene as chronic health issue to working environment, were not good candidates.

5.2.1.2 Seemann Composite Resin Infusion Moulding Process (SCRIMP) / Structural Reaction Injection Moulding (SRIM) The SCRIMP [82] originated from the hull production good for large complex structure with low pressure, while it is not cost efficient for smaller size domed shape. While the SRIM [83] involve with quick injection (1-4 min) of liquid low viscose reactants into a matched mold, fast polymerization to achieve the shaped part, the large thermal coefficient of liner expansion (TCLE) of the part which is depend on the properties of the reinforcement content and type, limit its widely application.

\subsubsection{Resin Transfer Mould (RTM) / Vacuum Assisted Resin Transfer Mould (VARTM) RTM} is an alternative process to autoclave. The pressure required is still higher than atmospheric pressure [84], low flow rate is favourable for good impregnation. When the additional vacuum is applied to 'evacuate' the mould preloaded with reinforcement before or during the resin injection, it is the widely known vacuum assisted RTM (VARTM) [85] process, also named Resin Infusion under Flexible Tooling (RIFT) [54]. The VARTM was derived from so the called Macro method for boat hull production developed in 1950 [54]. Ascribing to the closed mould in VARTM, the emission of styrene is less to a large extent. Even with a resin pressure as low as 1 bar, a high fibre volume fraction component can be achieved. The factors influencing the fibre wetting in VARTM process including the resin surface tension, fibre surface tension, dynamic contact angle of resin and fibre, adsorption and the desorption effects of volatile chemical constituent from resin and finishes on fibre surface[86]. 


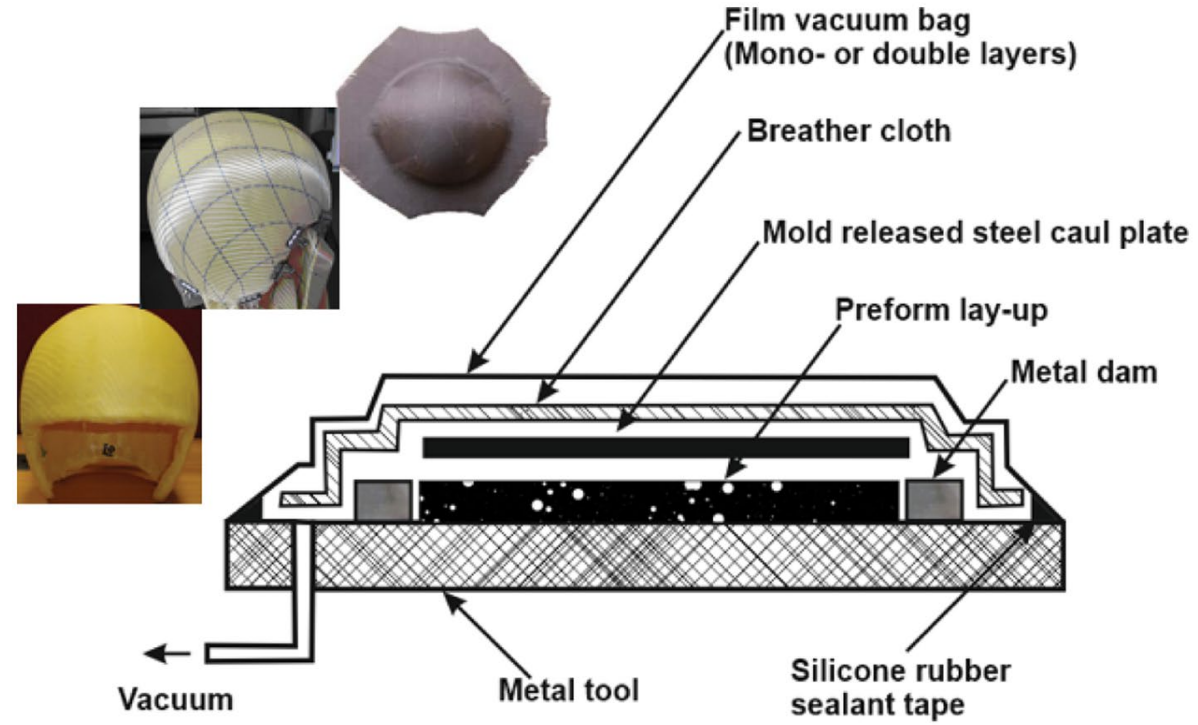

Fig. 10 Schematic of Vacuum Assisted Resin Infusion and outcome (Courtesy of [46, 87, 88])

5.2.1.4 Vacuum Assisted Resin Infusion Developing a suitable closed tool for the RTM/ VARTM process is costly, this capital investigation can be minimised by replacing the half mould with a flexible polymeric film, named vacuum assisted resin infusion (VARI), set up referring to Fig. 10. This method has advantage of capability of manufacturing large size or complex structures. Many physical specimen of highly dome helmet have successfully created by use of this method [46, 87]. Figure 11

5.2.1.5 Resin Film Infusion (RFI) / Compression Resin Transfer Moulding (CRTM) The RFI process [89] is similar to that of SCRIMP using low pressure and one-faced moulding tools, but the resin is introduced as a solid film, such that a well impregnation can be secured in the thickness direction. The CRTM process [90] was proposed to enhance the concepts used in RTM. The preform filled with resin has subjected to compaction before the moving upper mould directly in contact with the preform surface, lessen the chance for fibre distortion or damage induced by the friction.

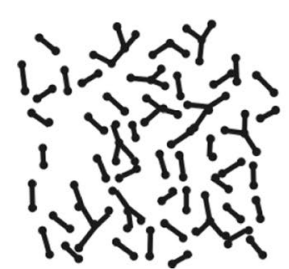

a

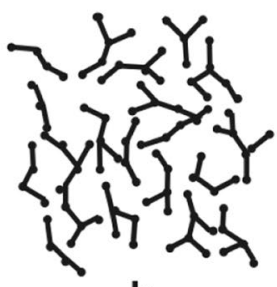

b

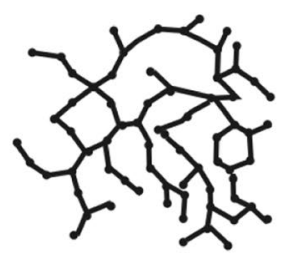

C

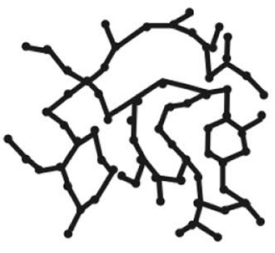

d

Fig. 11 Step-wise polymerization in curing process. (a) pre-polymer and curing agent prior to cure; (b) curing started: molecular size increasing. (c) Gelation achieved: continuous network d) full cure [94] 


\subsubsection{Influencing Factors in LCM}

There are many inertia factors hindering the creation of high quality part in LCM, and tremendous efforts in the literature have been tried to analysis and predict the resin filling and curing behaviour, giving solution to the common issues, which is associated with resin viscosity, friction, curing and permeability.

5.2.2.1 Curing and Resin Viscosity Curing is a progressive and exothermic chemical reaction process in a form of cross linking in thermoset resin, closely relating to the resin viscosity [91, 92]. The curing degree was found to have influence on the residual stress in the strain history monitoring, and the residual stress is likely to trigger cracking [93]. The curing has thus further impact on the chemical shrinkage, thermal expansion/contraction and curedependent mechanical properties of final part. The molecular size is increasing after curing [94], and the curing process is illustrated in Figure 11.

During the progressive process in curing, the cure kinetic, degree of cure, exothermic reaction of the resin, resin linear elastic and glass transition $(\mathrm{Tg})$ estimation are intensively studied in literature [95]. The cure kinetic for epoxy resin system was tried to be interpreted by Eq. (1):

$$
R(\alpha, t)=\frac{d \alpha}{d t}=A_{0} \exp \left(\frac{-E_{a}}{R T}\right)(1-\alpha)^{n}
$$

where $\mathrm{A}_{0}$ is the pre-exponential constant; $\mathrm{E}_{\mathrm{a}}$ is the activation energy; $\mathrm{R}$ is the universal gas constant; $\mathrm{m}$ and $\mathrm{n}$ are the orders of reaction (kinetic exponents).

Resin viscosity is one of the influencing factors to curing, it was suggested that the upper limit for viscosity in RTM should be $800 \mathrm{mPa}$.s ( $1 \mathrm{mPas}=1$ centipoise) [96]. And the viscosity plays an important role in fluid flowing pattern that affect the permeability as well.

5.2.2.2 Permeability and Friction Under Vacuum Like that in the thermo-mechanical forming, the frictional interaction between yarns and plies, or preforms and tools, in LCM will take place subjecting to vacuum before or during resin filling, having a significant effect on wrinkles formation [97]. Nesting phenomenon and geometrical variants [34] are induced by compaction in thickness direction. The compaction from vacuum will also get the pore pattern inside the structure changed and the permeability of fabric vary that will add uncertainty to the part quality.

When the resin flowing through the preforms from inlet to outlet, the major inertia it encountering are that come from viscosity of the resin, pressure profile and surface tension of fibre. The permeability is a dimensional quantity that can be normalized in the principle directions by Eq. (2) [99]:

$$
\mathrm{K}_{\mathrm{r}}^{\mathrm{us}}=\frac{\mu \varepsilon}{4 \mathrm{t} \triangle \mathrm{P}}\left\{\mathrm{r}_{\mathrm{f}}^{2}\left[2 \ln \left(\frac{\mathrm{r}_{\mathrm{f}}}{\mathrm{r}_{0}}\right)-1\right]+\mathrm{r}_{0}^{2}\right\}
$$

where $\mathrm{K}_{\mathrm{r}}^{\mathrm{us}}$ is the unsaturated permeability in $\mathrm{r}(\mathrm{x}, \mathrm{y}, \mathrm{z})$ position; $\mu$ is the resin viscosity; $\varepsilon$ is the porosity; $\Delta P$ is the pressure difference; $r_{0}$ is the inlet port radius; $r_{f}$ is the radius of the flow front. When the fabrics were sheared to accommodate the double domed shape, the permeability variants are likely to occur. It was observed that the permeability was in a linear increase between principle and secondary axis when shear angles up to $15^{\circ}$, while 
it presented non-linear when shear angles over $20^{\circ}$ [100]. More fluid flowing models have been reviewed in [34].

\section{Conclusions}

Current research has been carried out around two major generic synthetic fibres paraaramid and UHMPWE, which are good at performance in the ballistic resistant application, ascribing to their special chemical structure where the atoms are hold together by the strong covalent bonds. The high modulus, tensile strength and inertia to most of the environment are the critical features enable them to be the potential candidate for the ballistic composite helmet creation.

These two fibres can be constructed into different topologies, widely known as woven, unidirectional (UD), braid, stitched and tufted fabrics, they are divided into 1D, 2D and 3D preforms to talk about the flexibility respectively and presenting the advantage and drawbacks. Among of them, the woven fabric, including 2D and 3D woven, together with UD fabric are the two favourable fibre architectures used in ballistic protection, thanks for their high friction between yarns / fibres giving contribution. These architectures are conformed onto the double domed shape surface to achieve ideal preforming, where fibre continuity and free of wrinkles / folding or misalignment are desirable.

In preforming stage, the cut-dart technique is the conventional method used both for extensible and inextensible materials though, it will result in fibre discontinuity that is not good for strain wavy propagation away from the impact point, and lessen the material to engage in taking up more stress coming from projectile. On the other hand, the creep effect of UHMWPE fibre can be utilized to achieve the domed shape curvature, many trials in physical specimen have been successfully obtained. However, the creep effect is a highly polymeric type dependent method. Aligning with the material market shift is taking place from aramid dominating to UHMWPE taking up the place increasingly, combination of the structural integrity in 3D fabric made of inextensible aramid-based material with the creep effect of the UD / film made of UHMWPE fibre, are identified as a good choice for preforming.

For the manufacturing methods, VARI with less instrument investment is still the first priority, the other manufacturing methods reviewed in this paper are going to be alternatives offering informative parameters reference. In sum up, the fibre properties in nature, the fibre architectures, resin types and manufacturing methods are strongly interdependent to each other when considering the manufacturing the ballistic composite helmet, engineering are to be carried out with specific parameters selection. And current study has provide a good database.

Data Availability All data generated or analysed during this study are included in open published articles (and its supplementary information files) as indicated respectively.

Open Access This article is licensed under a Creative Commons Attribution 4.0 International License, which permits use, sharing, adaptation, distribution and reproduction in any medium or format, as long as you give appropriate credit to the original author(s) and the source, provide a link to the Creative Commons licence, and indicate if changes were made. The images or other third party material in this article are included in the article's Creative Commons licence, unless indicated otherwise in a credit line to the material. If material is not included in the article's Creative Commons licence and your intended use is not 
permitted by statutory regulation or exceeds the permitted use, you will need to obtain permission directly from the copyright holder. To view a copy of this licence, visit http://creativecommons.org/licenses/by/4.0/.

\section{References}

1. Hamouda, A.M.S., Sohaimi, R.M., Zaidi, A.M.A., Abdullah, S.: Materials and design issues for military helmets. Adv. Mil. Text. Pers (2012). https://doi.org/10.1533/9780857095572.1.103

2. Kulkarni, S.G., Gao, X.L., Horner, S.E., Zheng, J.Q., David, N.V.: Ballistic helmets - Their design, materials, and performance against traumatic brain injury. Compos. Struct. 101, 313-331 (2013). https://doi.org/10.1016/j.compstruct.2013.02.014

3. Carr, D.J., Lewis, E., Mahoney, P.F.: UK military helmet design and test methods. BMJ Mil Heal. 166, (2019). https://doi.org/10.1136/jramc-2018-001123

4. Jamroziak, K., Bajkowski, M., Bocian, M., Polak, S., Magier, M., Kosobudzki, M., Stepien, R.: Ballistic head protection in the light of injury criteria in the case of the Wz.93 combat helmet. Appl. Sci. 9, 1-16 (2019). https://doi.org/10.3390/app9132702

5. Breeze, J., Baxter, D., Carr, D., Midwinter, M.J.: Defining combat helmet coverage for protection against explosively propelled fragments. J. R. Army Med. Corps. 161, 9-13 (2015). https://doi.org/10. 1136/jramc-2013-000108

6. Zhang, T.G., Vargas-Gonzalez, L.R., Gurganus, J.C., Satapathy, S.S.: Effects of curvature and architecture on ballistic performance of UHMWPE helmets. ASME Int. Mech. Eng. Congr. Expo. Proc. 3, 1-9 (2019). https://doi.org/10.1115/IMECE2019-11566

7. Tan, L. Bin, Tse, K.M., Lee, H.P., Tan, V.B.C., Lim, S.P.: Performance of an advanced combat helmet with different interior cushioning systems in ballistic impact: Experiments and finite element simulations. Int. J. Impact Eng. 50, 99-112 (2012). https://doi.org/10.1016/j.ijimpeng.2012.06.003

8. Zheng, J.Q., Walsh, S.M.: Materials, manufacturing, and enablers for future soldier protection. (2016). https://doi.org/10.1016/B978-0-08-100406-7.00014-3

9. Gama, B.A., Gillespie, J.W.: Finite element modeling of impact, damage evolution and penetration of thick-section composites. Int. J. Impact Eng. 38, 181-197 (2011). https://doi.org/10.1016/j.ijimpeng. 2010.11.001

10. Lei, Z., Wang, Y., Qin, F., Qiu, W., Bai, R., Chen, X.: Multi-fiber strains measured by micro-Raman spectroscopy: Principles and experiments. Opt. Lasers Eng. 77, 8-17 (2016). https://doi.org/10. 1016/j.optlaseng.2015.07.005

11. Chu, Y.: Surface Modification to Aramid and UHMWPE fabrics to increase inter-yarn friction for improved ballistic performance.PhD thesis. Univ. Manchester; 2015. 1-244 (2015)

12. Zeng, L., Liu, X., Chen, X., Soutis, C.: Surface Modification of Carbon Fibres for Interface Improvement in Textile Composites. Appl. Compos. Mater. 25, 853-860 (2018). https://doi.org/10.1007/ s10443-018-9727-8

13. Kawabata, S., Niwa, M., Kawai, H.: 3-The finite-deformation theory of plain-weave fabrics part I: The biaxial-deformation theory. J. Text. Inst. 64, 21-46 (1973). https://doi.org/10.1080/00405007308630416

14. Hallander, P., Akermo, M., Mattei, C., Petersson, M., Nyman, T.: An experimental study of mechanisms behind wrinkle development during forming of composite laminates. Compos. Part A Appl. Sci. Manuf. 50, 54-64 (2013). https://doi.org/10.1016/j.compositesa.2013.03.013

15. Bel, S., Hamila, N., Boisse, P., Dumont, F.: Finite element model for NCF composite reinforcement preforming: Importance of inter-ply sliding. Compos. Part A Appl. Sci. Manuf. 43, 2269-2277 (2012). https://doi.org/10.1016/j.compositesa.2012.08.005

16. Walsh, S.M., Scott, B.R., Spagnuolo, D.M.: The Development of a Hybrid Thermoplastic Ballistic Material With Application to Helmets. Int'1 Ballist. Symp. 37, (2005)

17. Wichmann, M.H.G., Schulte, K., Wagner, H.D.: On nanocomposite toughness. Compos. Sci. Technol. 68, 329-331 (2008). https://doi.org/10.1016/j.compscitech.2007.06.027

18. Mesogitis, T.S., Skordos, A.A., Long, A.C.: Uncertainty in the manufacturing of fibrous thermosetting composites: A review. Compos. Part A Appl. Sci. Manuf. 57, 67-75 (2014). https://doi.org/10. 1016/j.compositesa.2013.11.004

19. Ahn, H., Kuuttila, N.E., Pourboghrat, F.: Mechanical analysis of thermo-hydroforming of a fiber-reinforced thermoplastic composite helmet using preferred fiber orientation model. J. Compos. Mater. 52, 31833198 (2018). https://doi.org/10.1177/0021998318762547

20. Tham, C.Y., Tan, V.B.C., Lee, H.P.: Ballistic impact of a KEVLAR® helmet: Experiment and simulations. Int. J. Impact Eng. 35, 304-318 (2008). https://doi.org/10.1016/j.ijimpeng.2007.03.008 
21. Li, Y.Q., Li, X.G., Gao, X.L.: Modeling of advanced combat helmet under ballistic impact. J. Appl. Mech. Trans. ASME. 82, 1-9 (2015). https://doi.org/10.1115/1.4031095

22. Eynde, J.O., Yu, A.W., Eckersley, C.P., Bass, C.R.: Blast wave protection in combat helmet design - a historical comparison. Ohio State Univ. Inj. Biomech. Symp. 1-14 (2018)

23. Min, S., Chen, X., Chai, Y., Lowe, T.: Effect of reinforcement continuity on the ballistic performance of composites reinforced with multiply plain weave fabric. Compos. Part B Eng. 90, 30-36 (2016). https://doi.org/10.1016/j.compositesb.2015.12.001

24. Gereke, T., Döbrich, O., Hübner, M., Cherif, C.: Experimental and computational composite textile reinforcement forming: A review. Compos. Part A Appl. Sci. Manuf. 46, 1-10 (2013). https://doi.org/ 10.1016/j.compositesa.2012.10.004

25. Carr, D.J., Lewis, E., Horsfall, I.: A systematic review of military head injuries. J. R. Army Med. Corps. 163, 13-19 (2017). https://doi.org/10.1136/jramc-2015-000600

26. Cheeseman, B.A., Bogetti, T.A.: Ballistic impact into fabric and compliant composite laminates. Compos. Struct. 61, 161-173 (2003). https://doi.org/10.1016/S0263-8223(03)00029-1

27. Bickerton, S., Simbeek, P., Guglielmi, S.E., Advani, S.G.: Investigation of draping and its effects on the mold filling process during manufacturing of a compound curved composite part. Compos. Part A. 801-816 (1997). https://doi.org/10.1016/S1359-835X(97)00033-X

28. Lebrun, G., Bureau, M.N., Denault, J.: Evaluation of bias-extension and picture-frame test methods for the measurement of intraply shear properties of PP/glass commingled fabrics. Compos. Struct. 61, 341-352 (2003). https://doi.org/10.1016/S0263-8223(03)00057-6

29. Chen, X., Lo, W.Y., Tayyar, A.E.: Mouldability of Angle-Interlock Woven Fabrics for Technical Applications. Text. Res. j. 72(3), 195-200 (2002). https://doi.org/10.1177/004051750207200302

30. Dixit, D., Pal, R., Kapoor, G., Stabenau, M.: Lightweight composite materials processing. Elsevier Ltd (2016). https://doi.org/10.1016/B978-0-08-100406-7.00006-4

31. Folgar, F.: Thermoplastic matrix combat helmet with carbon-epoxy skin for ballistic performance. Elsevier Ltd (2016). https://doi.org/10.1016/B978-1-78242-461-1.00015-7

32. Marissen, R.: Design with Ultra Strong Polyethylene Fibers. Mater. Sci. Appl. (2011). https://doi.org/ 10.4236/msa.2011.25042

33. Chen, X., Hearle, J.W.S.: Structural hierarchy in textile materials: An overview. Woodhead Publishing Limited (2010). https://doi.org/10.1533/9781845697211.1.3

34. Alotaibi, H., Jabbari, M., Soutis, C.: A numerical analysis of resin flow in woven fabrics: Effect of local tow curvature on dual-scale permeability. Materials (Basel). 14, 1-17 (2021). https://doi.org/10. 3390/ma14020405

35. Campbell, D.T., Cramer, D.R.: Hybrid thermoplastic composite ballistic helmet fabrication study. Mater. Process Eng. 52, (2008)

36. Sinha Ray, S., Okamoto, M.: Polymer/layered silicate nanocomposites: A review from preparation to processing. Prog. Polym. Sci. 28, 1539-1641 (2003). https://doi.org/10.1016/j.progpolymsci.2003.08. 002

37. Tracy H.J., Holt D.E., Tracy J.E.: Method for making a multipy continuous filament ballistic helmet. US Patent 4199388. (1980)

38. Jones, B., Mcelroy, M., Horvatich, V., Mears, J.: Method of producing light weight protective helmets for military and other uses. US Patent 8313602 B2. (2012)

39. Perciballi W. J.: Ballistic Helmet and Fabrication method. US Patent 8,850,612 B1. (2014)

40. Medwell R.T.A: Composite Helmet. US Patents 4656674. (1987)

41. Cheese M.: Method of Making a Helmet. US Patent 7228571 B2. (2007)

42. Trentacosta, J., Walker, W.: Method of Making a Helmet. US Patent 9050756 B2. (2015)

43. Chen, X., Taylor, L.W., Tsai, L.J.: An overview on fabrication of three-dimensional woven textile preforms for composites. Text. Res. J. 81, 932-944 (2011). https://doi.org/10.1177/0040517510392471

44. Yu, W.R., Harrison, P., Long, A.: Finite element forming simulation for non-crimp fabrics using a non-orthogonal constitutive equation. Compos. Part A Appl. Sci. Manuf. 36, 1079-1093 (2005). https://doi.org/10.1016/j.compositesa.2005.01.007

45. Busgen, A.: Woven Fabric having a Bulging Zone and Method and Apparatus of Forming Same. US Patent 6000442. (1999)

46. Roedel, C., Chen, X.: Innovation and Analysis of Police Riot Helmets with Continuous Textile Reinforcement for Improved Protection. 2, 187-194 (2007). https://doi.org/10.1109/cesa.2006.4281648

47. Zhang, Y., Sun, F., Wang, Y., Chen, L., Pan, N.: Study on intra/inter-ply shear deformation of three dimensional woven preforms for composite materials. Mater. Des. 49, 151-159 (2013). https://doi.org/10.1016/j.matdes.2013.02.025 
48. Charmetant, A., Orliac, J.G., Vidal-Sallé, E., Boisse, P.: Hyperelastic model for large deformation analyses of 3D interlock composite preforms. Compos. Sci. Technol. 72, 1352-1360 (2012). https://doi.org/10.1016/j.compscitech.2012.05.006

49. El Said, B., Green, S., Hallett, S.R.: Kinematic modelling of 3D woven fabric deformation for structural scale features. Compos. Part A Appl. Sci. Manuf. 57, 95-107 (2014). https://doi.org/10. 1016/j.compositesa.2013.11.006

50. Jacquot, P.B., Wang, P., Soulat, D., Legrand, X.: Analysis of the preforming behaviour of the braided and woven flax/polyamide fabrics. J. Ind. Text. 46, 698-718 (2016). https://doi.org/10. $1177 / 1528083715591592$

51. Lee, J.S., Hong, S.J., Yu, W.R., Kang, T.J.: The effect of blank holder force on the stamp forming behavior of non-crimp fabric with a chain stitch. Compos. Sci. Technol. 67, 357-366 (2007). https://doi.org/10.1016/j.compscitech.2006.09.009

52. Dell'Anno, G., Treiber, J.W.G., Partridge, I.K.: Manufacturing of composite parts reinforced through-thickness by tufting. Robot. Comput. Integr. Manuf. 37, 262-272 (2016). https://doi.org/ 10.1016/j.rcim.2015.04.004

53. Liu, L.S., Zhang, T., Wang, P., Legrand, X., Soulat, D.: Influence of the tufting yarns on formability of tufted 3-Dimensional composite reinforcement. Compos. Part A Appl. Sci. Manuf. 78, 403-411 (2015). https://doi.org/10.1016/j.compositesa.2015.07.014

54. Williams, C., Summerscales, J., Grove, S.: Resin infusion under flexible tooling (RIFT): A review. Compos. Part A Appl. Sci. Manuf. 27, 517-524 (1996). https://doi.org/10.1016/1359-835X(96) 00008-5

55. Okine, R.K.: Analysis of Forming Parts from Advanced Thermoplastic Composite Sheet Materials. J. Thermoplast. Compos. Mater. 2, 50-76 (1989). https://doi.org/10.1177/089270578900200104

56. Campbell, F.: Structural Composite Materials. ASM International. ASM Int. 612, (2010)

57. Monaghan, P.F., Brogan, M.T., Oosthuizen, P.H.: Heat transfer in an autoclave for processing thermoplastic composites. Compos. Manuf. 2, 233-242 (1991). https://doi.org/10.1016/0956-7143(91) 90145-7

58. Rudd, C.D., Long, A.C., Kendall, K.N., Mangin, C.: Liquid moulding technologies: Resin transfer moulding, structural reaction injection moulding and related processing techniques. Woodhead Publ. Ltd., USA (1997)

59. Simbolon, M.R.: Investigation on Steam-based System for Creepforming Dyneema R Hemisphere Preform. pse.edu. (2015)

60. Potter, K., Khan, B., Wisnom, M., Bell, T., Stevens, J.: Variability, fibre waviness and misalignment in the determination of the properties of composite materials and structures. Compos. Part A Appl. Sci. Manuf. 39, 1343-1354 (2008). https://doi.org/10.1016/j.compositesa.2008.04.016

61. Hamouda, A.M.S., Sohaimi, R.M., Zaidi, A.M.A., Abdullah, S.: Materials and design issues for military helmets. Woodhead Publishing Limited (2012)

62. Gorczyca-Cole, J.L., Sherwood, J.A., Chen, J.: A friction model for thermostamping commingled glass-polypropylene woven fabrics. Compos. Part A Appl. Sci. Manuf. 38, 393-406 (2007). https://doi.org/10.1016/j.compositesa.2006.03.006

63. Marissen, R., Duurkoop, D., Hoefnagels, H., Bergsma, O.K.: Creep forming of high strength polyethylene fiber prepregs for the production of ballistic protection helmets. Compos. Sci. Technol. 70, 1184-1188 (2010). https://doi.org/10.1016/j.compscitech.2010.03.003

64. Dangora, L.M., Mitchell, C.J., Sherwood, J., Parker, J.C.: Deep-drawing forming trials on a cross-ply thermoplastic lamina for helmet preform manufacture. J. Manuf. Sci. Eng. Trans. ASME. 139, 1-8 (2017). https://doi.org/10.1115/1.4034791

65. Nosrat-Nezami, F., Gereke, T., Eberdt, C., Cherif, C.: Characterisation of the shear-tension coupling of carbon-fibre fabric under controlled membrane tensions for precise simulative predictions of industrial preforming processes. Compos. Part A Appl. Sci. Manuf. 67, 131-139 (2014). https://doi.org/10. 1016/j.compositesa.2014.08.030

66. Breuer, U., Neitzel, M., Ketzer, V., Reinicke, R.: Deep drawing of fabric-reinforced thermoplastics: Wrinkle formation and their reduction. Polym. Compos. 17, 643-647 (1996). https://doi.org/10.1002/ pc. 10655

67. Kuuttila, N.E.: Composite Thermo-hydroforming of military ballistic helmets. ProQuest. (2014)

68. Chen, S., McGregor, O.P.L., Harper, L.T., Endruweit, A., Warrior, N.A.: Defect formation during preforming of a bi-axial non-crimp fabric with a pillar stitch pattern. Compos. Part A Appl. Sci. Manuf. 91, 156-167 (2016). https://doi.org/10.1016/j.compositesa.2016.09.016

69. Dangora, L.M., Mitchell, C.J., Sherwood, J.A.: Predictive model for the detection of out-of-plane defects formed during textile-composite manufacture. Compos. Part A Appl. Sci. Manuf. 78, 102-112 (2015). https://doi.org/10.1016/j.compositesa.2015.07.011 
70. Breuer, U., Neitzel, M., Ketzer, V., Reinicke, R.: Deep Drawing of Fabric-reinforced Thermoplastics: Wrinkle Formation and Their Reduction. Polym. Compos. (1996). https://doi.org/10.1002/pc.10655

71. Folgar F.: Ballistic helmets and method of manufacture thereof. US Patent 10448695. (2019)

72. Harrison, P., Gomes, R., Curado-Correia, N.: Press forming a 0/90 cross-ply advanced thermoplastic composite using the double-dome benchmark geometry. Compos. Part A Appl. Sci. Manuf. 54, 56-69 (2013). https://doi.org/10.1016/j.compositesa.2013.06.014

73. Long, A.C., Clifford, M.J.: Composite forming mechanisms and materials characterisation. Compos. Form. Technol. A Vol. Woodhead Publ. Ser. Text. 1-21 (2007). https://doi.org/10.1533/9781845692537.1

74. Liang, B., Hamila, N., Peillon, M., Boisse, P.: Analysis of thermoplastic prepreg bending stiffness during manufacturing and of its influence on wrinkling simulations. Compos. Part A Appl. Sci. Manuf. 67, 111-122 (2014). https://doi.org/10.1016/j.compositesa.2014.08.020

75. Ten Thije, R.H.W., Akkerman, R., Ubbink, M., Van Der Meer, L.: A lubrication approach to friction in thermoplastic composites forming processes. Compos. Part A Appl. Sci. Manuf. 42, 950-960 (2011). https://doi.org/10.1016/j.compositesa.2011.03.023

76. Van West, B.P., Pipes, R.B., Keefe, M.: A simulation of the draping of bidirectional fabrics over arbitrary surfaces. J. Text. Inst. 81, 448-460 (1990). https://doi.org/10.1080/00405009008658722

77. Hamila, N., Boisse, P.: Locking in simulation of composite reinforcement deformations. Analysis and treatment. Compos. Part A Appl. Sci. Manuf. 53, 109-117 (2013). https://doi.org/10.1016/j. compositesa.2013.06.001

78. White, K., Yeager, M., Sherwood, J., Bogetti, T., Cline, J.: Material characterization and finite element modeling for the forming of highly oriented UHMWPE thin film and unidirectional cross-ply composites. 33rd Tech. Conf. Am. Soc. Compos. 2018. 1, 497-511 (2018). https://doi.org/10.12783/ $\operatorname{asc} 33 / 25944$

79. Potter, K.D., Campbell, M., Langer, C., Wisnom, M.R.: The generation of geometrical deformations due to tool/part interaction in the manufacture of composite components. Compos. Part A Appl. Sci. Manuf. 36, 301-308 (2005). https://doi.org/10.1016/j.compositesa.2004.06.002

80. Parlevliet, P.P., Bersee, H.E.N., Beukers, A.: Residual stresses in thermoplastic composites-A study of the literature-Part I: Formation of residual stresses. Compos. Part A Appl. Sci. Manuf. 37, 1847-1857 (2006). https://doi.org/10.1016/j.compositesa.2005.12.025

81. Minchenkov, K., Vedernikov, A., Safonov, A., Akhatov, I.: Thermoplastic pultrusion: A review. Polymers (Basel). 13, 1-36 (2021). https://doi.org/10.3390/polym13020180

82. Han, K., Jiang, S., Zhang, C., Wang, B.: Flow modeling and simulation of SCRIMP for composites manufacturing. Compos. Part A Appl. Sci. Manuf. 31, 79-86 (2000). https://doi.org/10.1016/S1359835X(99)00053-6

83. González-Romero, V.M., Macosko, C.W.: Process parameters estimation for structural reaction injection molding and resin transfer molding. Polym. Eng. Sci. 30, 142-146 (1990). https://doi.org/10. 1002/pen.760300303

84. Patel, N., Rohatgi, V., Lee, L.J.: Influence of processing and material variables on resin-fiber interface in liquid composite molding. Polym. Compos. 14, 161-172 (1993). https://doi.org/10.1002/pc.750140210

85. Naik, N.K., Sirisha, M., Inani, A.: Permeability characterization of polymer matrix composites by RTM/VARTM. Prog. Aerosp. Sci. 65, 22-40 (2014). https://doi.org/10.1016/j.paerosci.2013.09.002

86. Hayward, J.S., Harris, B.: The effect of vacuum assistance in resin transfer moulding. Compos. Manuf. 1, 161-166 (1990). https://doi.org/10.1016/0956-7143(90)90163-Q

87. Zahid, B., Chen, X.: Manufacturing of single-piece textile reinforced riot helmet shell from vacuum bagging. J. Compos. Mater. 47, 2343-2351 (2013). https://doi.org/10.1177/0021998312457703

88. Creech, G., Pickett, A.K.: Meso-modelling of Non-crimp Fabric composites for coupled drape and failure analysis. J. Mater. Sci. 41, 6725-6736 (2006). https://doi.org/10.1007/s10853-006-0213-6

89. Struzziero, G., Teuwen, J.J.E., Skordos, A.A.: Numerical optimisation of thermoset composites manufacturing processes: A review. Compos. Part A. 124, 105499 (2019). https://doi.org/10.1016/j. compositesa.2019.105499

90. Merotte, J., Simacek, P., Advani, S.G.: Resin flow analysis with fiber preform deformation in through thickness direction during Compression Resin Transfer Molding. Compos. Part A Appl. Sci. Manuf. 41, 881-887 (2010). https://doi.org/10.1016/j.compositesa.2010.03.001

91. Dusi, M.R., Lee, W.I., Ciriscioli, P.R., Springer, G.S.: Cure Kinetics and Viscosity of Fiberite 976 Resin. J. Compos. Mater. 21, 243-261 (1987). https://doi.org/10.1177/002199838702100304

92. Karkanas, P.I., Partridge, I.K.: Cure modeling and monitoring of epoxy/amine resin systems. I. Cure kinetics modeling. J. Appl. Polym. Sci. 77, 1419-1431 (2000).

93. Qi, Y., Jiang, D., Ju, S., Zhang, J.: Investigation of strain history in fast and conventional curing epoxy matrix composites by FBGs. Compos. Sci. Technol. 159, 18-24 (2018). https://doi.org/10.1016/j. compscitech.2018.02.019 
94. Johnston, A., Vaziri, R., Poursartip, A.: A plane strain model for process-induced deformation of laminated composite structures. J. Compos. Mater. 35, 1435-1469 (2001). https://doi.org/10.1106/ YXEA-5MH9-76J5-BACK

95. Baran, I.: Pultrusion processes for composite manufacture. Adv. Compos. Manuf. Process Des. Elsevier Ltd. (2015). https://doi.org/10.1016/B978-1-78242-307-2.00016-6

96. Summerscales, J., Searle, T.J.: Low-pressure (vacuum infusion) techniques for moulding large composite structures. Proc. Inst. Mech. Eng. Part L J. Mater. Des. Appl. 45-58 (2005). https://doi.org/10. 1243/146442005X10238

97. Nosrat, F., Gereke, T., Cherif, C.: Composites : Part A Analyses of interaction mechanisms during forming of multilayer carbon woven fabrics for composite applications. Compos. PART A. 84, 406416 (2016). https://doi.org/10.1016/j.compositesa.2016.02.023

98. Lomov, S.V., Verpoest, I., Peeters, T., Roose, D., Zako, M.: Nesting in textile laminates: Geometrical modelling of the laminate. Compos. Sci. Technol. 63, 993-1007 (2003). https://doi.org/10.1016/ S0266-3538(02)00318-4

99. Shenoi, R.A., Wilson, P.A., Weitzenbo, J.R.: Radial flow permeability measurement . Part A : Theory. Compos. PART A. 30, 781-796 (1999). https://doi.org/10.1016/S1359-835X(98)00183-3

100. Aranda, S., Berg, D.C., Dickert, M., Drechsel, M., Ziegmann, G.: Influence of shear on the permeability tensor and compaction behaviour of a non-crimp fabric. Compos. Part B Eng. 65, 158-163 (2014). https://doi.org/10.1016/j.compositesb.2014.02.005

Publisher's Note Springer Nature remains neutral with regard to jurisdictional claims in published maps and institutional affiliations. 